\title{
PENGARUH SUPERVISI AKADEMIK DAN MOTIVASI KERJA TERHADAP KOMPETENSI PROFESIONAL
}

\author{
Nurjaya' Anis Syamsu Rizal', \\ Universitas Pamulang \\ dosen01605@unpam.ac.id \\ *Korespondensi
}

Naskah diterima: 25 Maret 2021, direvisi: 30 April 2021, disetujui: 30 Juni 2021

\section{Abstrak}

Tujuan dari penelitian ini adalah sebagai berikut: (1) Mengetahui pengaruh supervisi akademik kepala sekolah terhadap kompetensi profesional guru. (2) Mengetahui pengaruh motivasi kerja guru terhadap kompetensi profesional. (3) Mengetahui pengaruh secara bersama-sama supervisi akademik dan motivasi kerja terhadap kompetensi profesional guru SD Al-lkhlas Cipete. Populasi dalam penelitian ini adalah guru SD Al-lkhlas Cipete dengan jumlah 84 orang. Sedangkan jumlah sampel penelitian adalah 84 orang. Berdasarkan hasil penelitian dan pembahasan diperoleh kesimpulan, sebagai berikut: 1) Ada pengaruh supervisi akademik kepala sekolah terhadap kompetensi profesional guru SD Al-lkhlas Cipete. Pengaruh positif dan signifikan dari supervisi akademik terhadap kompetensi profesional guru SD Al-lkhlas Cipete sebesar 53,5\%. 2) Ada pengaruh motivasi kerja guru terhadap kompetensi profesional guru SD Al-lkhlas Cipete. Motivasi kerja berpengaruh positif terhadap kompetensi profesional sebesar 42,8\%. 3) Ada pengaruh supervisi akademik kepala sekolah dan motivasi kerja guru secara brsama-sama terhadap kompetensi profesional guru SD Al-lkhlas Cipete sebesar $54,65 \%$.

Kata Kunci : Supervisi Akademik, Motivasi, dan Kompetensi Profesional

\section{Abstract}

The aims of this research are (1) to know how much influence the academic supervision of the professional competence of teachers, (2) to know how much influence the motivation to work towards professional competence of teachers, (3) to know how much influence the academic supervision and motivation to work together towards competence professional teacher in SD Al-lkhlas Cipete. The population in this research were teachers at the SD Al-lkhlas Cipete are 84 people. The sample in this research were selected using proportional random sampling and the number of samples set 84 respondents. The results of the requirements of the research, are: 1) any effect of the academic supervision on the professional competence of teachers. There is a positive and significant influence of the academic supervision of the professional competency teacher motivation in SD Al-lkhlas Cipete of 53,5\%. 2) any effect of work on the professional competence of teachers in SD Al-lkhlas Cipete. Work motivation positive and significant impact on the proffesional competence of teachers of $42,8 \%$. 3) any effect of academic supervision and motivation to work together towards competence professional teacher in SD Al-lkhlas Cipete of 54,65\%.

Keywords: Academic Supervision, Motivation, Professional Competence. 


\section{PENDAHULUAN}

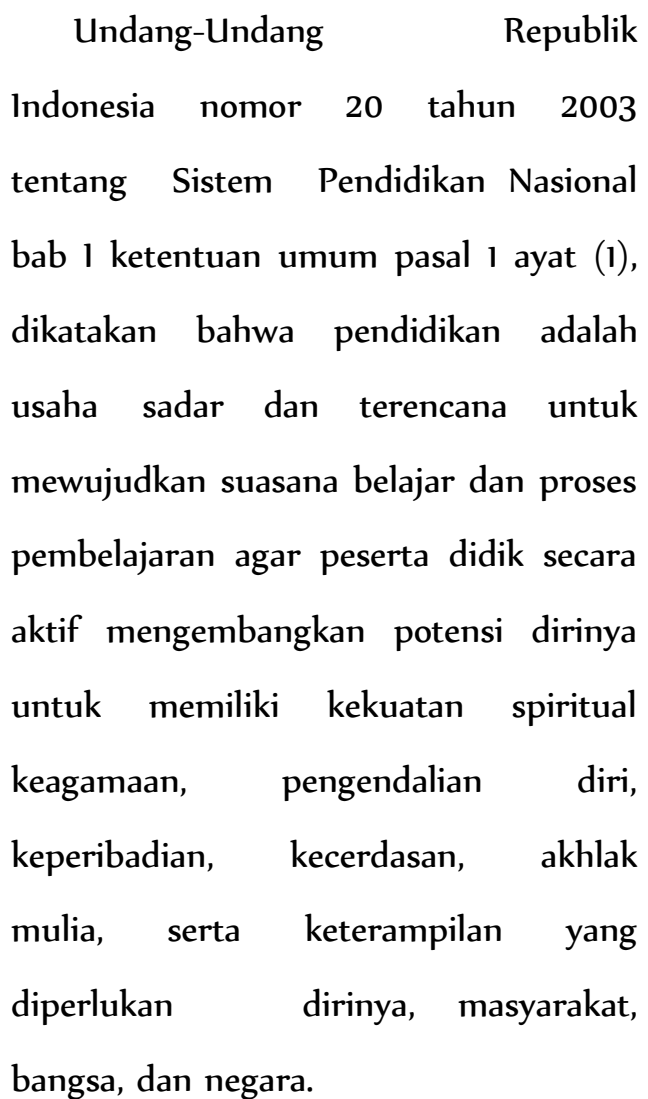

Selanjutnya berdasarkan UndangUndang Republik Indonesia nomor 14 tahun 2005 tentang Guru dan Dosen pada bab 1 Ketentuan Umum pasal 1 ayat 1 dinyatakan bahwa: Guru adalah pendidik profesional dengan tugas utama mendidik, mengajar, membimbing, mengarahkan, melatih, menilai, dan mengevaluasi peserta didik pada pendidikan anak usia dini jalur pendidikan formal, pendidikan dasar, dan pendidikan menengah.

$$
\text { Menurut Mulyasa }
$$

kompetensi profesional merupakan kemampuan guru dalam menguasai materi pembelajaran dalam rangka membimbing siswa mendapatkan kompetensi yang ditetapkan. Pengetahuan profesional mempunyai landasan yang dijadikan petunjuk guru dalam mengembangkan kompetensi profesionalnya.

Pembinaan pendidik profesional menurut Suryadi (2014: 91) harus berlangsung secara berkesinambungan, karena pada dasarnya guru harus merupakan seorang pembelajar sepanjang hayat (a lifelong learner). Sebagai seorang profesional dan penyandang sertifikat pendidik, guru berkewajiban untuk mempertahankan kemampuan profesionalnya dan kinerjanya.

Hasil wawancara dengan Kepala SD Al-lkhlas Cipete diketahui bahwa 56\% dari 84 guru SD Al-lkhlas Cipete telah bersertifikat profesional. Akan tetapi, hasil supervisi oleh Yayasan menunjukkan sebagian besar Guru SD Al-lkhlas Cipete mempunyai kemampuan penguasaan materi pembelajaran yang kurang luas dan kurang mendalam. Dalam artian, guru SD Al-lkhlas Cipete belum memenuhi kompetensi profesional menurut 
Standar Nasional Pendidikan, penjelasan Pasal 28 ayat (3) butir c dikemukakan bahwa kompetensi profesional adalah kemampuan penguasaan materi pembelajaran secara luas dan mendalam yang memungkinkan membimbing peserta didik memenuhi standar kompetensi yang ditetapkan dalam Standar Nasional Pendidikan.

Observasi awal menunjukkan kurangnya kompetensi profesional kerja dari guru SD Al-lkhlas Cipete. Masih ada guru yang menggunakan metode ceramah, sedangkan materinya membutuhkan metode demonstrasi atau metode lainnya. Selain itu, guru SD Allkhlas Cipete masih kurang disiplin dalam kehadiran di kelas. Hasil wawancara dengan Kepala Sekolah SD Al-lkhlas Cipete, mengatakan bahwa masih ada guru yang masuk ke kelas 5-10 menit setelah bel berbunyi.

Hasil wawancara awal pada beberapa guru SD Al-lkhlas Cipete pada hari, menunjukkan bahwa hal ini dikarenakan pembinaan atau supervisi dari kepala sekolah secara individu jarang dilaksanakan, yang ada supervisi secara kelompok. Kepala sekolah terbukti jarang melaksanakan supervisi, bahkan pernah dalam satu tahun pelajaran ada beberapa guru yang mengaku tidak pernah disupervisi oleh kepala sekolahnya. Jarangnya supervisi akademik dilakukan, menyebabkan rendahnya kompetensi profesional guru dan rendahnya motivasi kerja guru SD Al-lkhlas Cipete.

Usaha meningkatkan kemampuan profesional dapat dilakukan dengan memberikan bantuan profesional kepada guru dalam bentuk penyegaran, konsultasi, bimbingan, dan kegiatan yang mungkin dilakukan. Sebelumnya antara kepala sekolah membangun kesepakatan kualitas mengajar diinginkan, sehingga layanan belajar dapat lebih baik dan ada peningkatan terus menerus. Untuk menjaga kualitas layanan tetap terjaga, maka supervisi menjadi hal yang penting dalam memberikan bantuan kepada guru (Sagala, 2013: 194).

Hardoko, Haryono, dan Yusuf (2017) menyebutkan supervisi akademik yaitu kegiatan bantuan kepada guru untuk membantu guru dalam proses Kegiatan Belajar Mengajar (KBM) terdiri dari kegiatan 
perencanaan, pelaksanaan, dan penilaian. Supaya tercapai tujuan pembelajaran. Sehingga supervisi akademik dapat meningkatkan kualitas pembelajaran. Disebutkan Mulyasa (2015) bahwa tujuan supervisi akademik yaitu meningkatkan kemampuan profesional guru dan peningkatan kualitas pembelajaran.

Penelitian yang dilakukan oleh Aribowo, Su'ad, dan Madjdi (2020) terlihat bahwa supervisi akademik berpengaruh terhadap kompetensi profesional guru sebesar $32,0 \%$. Penelitian lain yang dilakukan oleh Muhajirin, Prihatin, dan Yusuf (2017), menunjukkan bahwa Hasil analisis regresi menunjukkan bahwa pengaruh supervisi akademik terhadap profesionalisme guru sebesar 0, 196 dengan nilai signifikansi sebesar 0,014 lebih kecil dari 0,05.

Dengan demikian pengaruh supervisi akademik kepala sekolah terhadap motivasi kerja sebesar $19,6 \%$, sehingga supervisi akademik kepala sekolah berpengaruh positif dan signifikan terhadap profesionalisme guru SMA/MA. Hal tersebut mengindikasikan bahwa supervisi akademik kepala sekolah beperan dalam rangka meningkatkan profesionalisme guru.

Faktor berikut yang mempengaruhi kompetensi profesional adalah motivasi kerja. Motivasi merupakan setiap kegiatan yang mendorong, meningkatkan kinerja dan mengajak tenaga kerja atau pegawai untuk bekerja lebih efektif. Dengan motivasi dapat menimbulkan etos kerja yang baik. Karena pentingnya peran manusia dalam organisasi sekolah, maka pimpinan organisasi sekolah harus dapat memberikan "motivasi", yang diartikan sebagai pemberian pembinaan atau bimbingan kepada para anggota organisasi sekolah, agar mereka mau dan ikhlas bekerja dengan sebaik mungkin demi tercapainya tujuan organisasi sekolah. Pengaruh motivasi kepala sekolah untuk meningkatkan kompetensi profesional guru sangat penting, antara lain agar motivasi yang diberikan dalam bentuk pembinaan atau bimbingan tersebut dapat memotivasi setiap guru dalam melakukan aktivitas dan target yang diharapkan.

Pada penelitian yang dilakukan oleh Kurniawan (2017) menunjukkan bahwa 
terdapat pengaruh yang signifikan Motivasi kerja guru terhadap kompetensi profesional guru pada MIN Air Joman dan MIS MPI Binjai Serbangan kabupaten Asahan yaitu $83,2 \%$ dan terdapat pengaruh yang signifikan secara bersamaan antara motivasi kerja dan kesejahteraan guru terhadap kompetensi profesional guru pada MIN dan MIS Air Joman kabupaten Asahan yaitu 79,3\%.

Penelitian lain yang dilakukan oleh Muhajirin, Prihatin, dan Yusuf (2017), hasil analisis regresi menunjukkan bahwa pengaruh motivasi kerja terhadap profesionalisme guru sebesar 0, 404 dengan nilai signifikansi sebesar 0, 000 lebih kecil dari 0, 05. Dengan demikian pengaruh supervisi akademik kepala sekolah terhadap motivasi kerja sebesar 40, 4\%. Sehingga motivasi kerja berpengaruh positif dan signifikan terhadap profesionalisme guru SMA/MA. Hal tersebut mengindikasikan bahwa motivasi kerja berpengaruh terhadap profesionalisme guru.

Dari pemaparan di atas, maka penelitian ini akan mengungkapkan seberapa besar pengaruh supervisi akademik terhadap kompetensi profesional guru, dan seberapa besar pengaruh motivasi kerja guru terhadap kompetensi profesional guru SD AlIkhlas Cipete, Jakarta Selatan.

Berdasarkan uraian latar belakang dan penelitian terdahulu di atas, serta dengan adanya identifikasi masalah tersebut, maka rumusan masalah pada penelitian ini adalah:

1. Apakah supervisi akademik kepala sekolah berpengaruh terhadap kompetensi profesional?

2. Apakah motivasi kerja guru berpengaruh terhadap kompetensi profesional guru?

3. Apakah supervisi akademik kepala sekolah dan motivasi kerja guru berpengaruh secara simultan terhadap kompetensi profesional?

\section{METODE PENELITIAN}

Jenis penelitian yang digunakan dalam penelitian ini adalah penelitian kuantitatif. Metode kuantitatif merupakan metode ilmiah karena telah memenuhi kaidah-kaidah ilmiah yaitu empiris, obyektif, terukur, rasional, dan sistematis (Sugiyono, 2019:7). Disebut penelitian kuantitatif karena data penelitian berupa angka-angka dan analisis menggunakan statistik. Berdasarkan metodenya, jenis penelitian 
ini merupakan penelitian kuantitatif deskriptif. Penelitian deskriptif ini merupakan gambaran atas deskripsi suatu data yang dilakukan dalam hal untuk mengetahui adanya hubungan antara variabel bebas dan variabel terikat. Adapun sumber data dalam penelitian ini adalah data primer. Data Primer adalah sumber data yang langsung memberikan data kepada pengumpul data (Sugiyono, 2019:137).

Populasi menurut Sugiyono (2019: 80) adalah wilayah generalisasi yang terdiri atas: obyek/subyek yang mempunyai kualitas dan karakteristik tertentu yang ditetapkan oleh peneliti untuk dipelajari dan kemudian ditarik kesimpulannya. Populasi dalam penelitian ini adalah Seluruh guru SD Al-lkhlas Cipete, baik guru tetap yayasan maupun guru tidak tetap. Target populasi adalah guru di SD Allkhlas Cipete dengan jumlah 84 orang.

Arikunto

(2006:

mengemukakan: sampel adalah sebagian atau wakil populasi yang diteliti. Sampel dalam penelitian ini adalah guru SD $\mathrm{Al}-$ lkhlas Cipete yang terpilih sebagai unit analisis. Apabila jumlah rsponden kurang dari 100, sampel diambil semua sehingga penelitiannya merupakan penelitian populasi. Jadi sampel penelitian sejumlah 84 Guru SD Al-
Ikhlas Cipete yang merupakan populasi penelitian.

Metode pengumpulan data yang digunakan dalam penelitian ini adalah metode survey, yaitu teknik pengumpulan dan analisis data berupa opini dari subyek yang diteliti melalui kuesioner, wawancara dan observasi.

Analisis data ini bertujuan untuk mengetahui peran masing-masing variabel inedpenden dalam mempengaruhi variabel dependen. Dan data penelitian tersebut akan di hitung menggunakan program software statistik SPSS (Statistical package for social science) versi 24.0.

\section{PEMBAHASAN}

DAN

HASIL

\section{PENELITIAN}

\section{Gambaran Umum Subjek Penelitian}

SD Islam Al Ikhlas sebuah sekolah swasta lslam yang memiliki visi melahirkan siswa yang berjiwa pemimpin, cerdas, dan berakhlakul karimah. Visi mulia yang disosialisasikan kepada seluruh stakeholder SD Islam Al lkhlas, mulai dari kepala sekolah, guru, karyawan, orang tua murid bahkan murid-murid SD lslam Al Ikhlas.

Sekolah Islam Al ikhlas adalah sekolah yang dimiliki oleh sebuah masjid dibawah naungan Yayasan Masjid Al ikhlas (YMAl). Yayasan Masjid Al Ikhlas adalah masjid yang didirikan 
pada tanggal II April 1967 dan berlokasi di Jl. Cipete 3 No. 3 Rt 06 Rw 04 Kelurahan Cipete Selatan, Kecamatan Cilandak Jakarta Selatan. Berdiri pada tahun 1980 tepatnya dibulan Juli. Dan yang pertama kali menjabat sebagai kepala sekolah adalah Drs H. Sadikin A.H.

\section{KESIMPULAN}

Berdasarkan hasil penelitian dan pembahasan pada bab sebelumnya diperoleh kesimpulan, sebagai berikut:

1. Ada pengaruh supervisi akademik kepala sekolah terhadap kompetensi profesional guru SD Al Ikhlas Cipete. Hal tersebut dibuktikan dengan nilai $\mathrm{t}$ hitung 10,001 lebih besar dari $t$ tabel 1,960 dengan tingkat signifikan $0,000 \mathrm{di}$ bawah batas toleransi kesalahan $5 \%$ atau tingkat kepercayaan $100 \%$ di atas atau tingkat kepercayaan 95\% yang telah disyaratkan dalam perhitungan. Besarnya koefesien regresi pada model regresi sederhana supervisi akademik kepala sekolah terhadap kompetensi kerja guru sebesar 0,535 artinya bahwa supervisi akademik kepala sekolah berpengaruh positif terhadap kinerja guru sebesar 0,535 dan apabila supervisi akademik kepala sekolah ditingkatkan 1\% maka akan meningkatkan kompetensi akademik sebesar 53,5\%. Hasil tersebut sekaligus menjawab hipotesis yang berbunyi ada pengaruh supervisi akademik kepala sekolah terhadap kompetensi profesional guru SD Al Ikhlas Cipete.

2. Ada pengaruh motivasi kerja guru terhadap kompetensi profesional guru SD Al Ikhlas Cipete. Hasil perhitungan regresi sederhana motivasi kerja guru terhadap kompetensi profesional guru diketahui bahwa nilai $\mathrm{t}$ hitung 5,114 lebih besar dari $t_{\text {tabel }}$ 1,960 dengan tingkat signifikan 0,000 dibawah batas toleransi kesalahan 0,05 atau dengan tingkat kepercayaan 100\% motivasi kerja guru dalam mempengaruhi kompetensi profesional guru. Adapun pengaruh variabel motivasi kerja guru terhadap kompetensi profesional guru sebesar 0,428 hal ini diketahui dari nilai koefesien regresi sebesar 0,428 yang berarti bahwa apabila motivasi kerja guru ditingkatkan sebesar 1\% maka akan meningkatkan kompetensi kerja guru sebesar 42,8\%. Hasil perhitungan menjawab hipotesis 
penelitian yang berbunyi: Ada pengaruh motivasi kerja guru terhadap kompetensi profesional guru SD Al lkhlas Cipete.

3. Ada pengaruh supervisi akademik kepala sekolah dan motivasi kerja guru terhadap kompetensi profesional guru SD Al lkhlas Cipete. Nilai F hitung sebesar 54,651 dan signifikansi (probability P) sebesar 0,000 yang menunjukkan bahwa hipotesis nol (Ho) ditolak karena signikan (P) kurang dari taraf signifikan $\alpha=$ 0,05. Dengan ditolaknya Ho maka hipotesis alternatif diterima, yang berarti ada pengaruh supervisi akademik kepala sekolah dan motivasi kerja guru terhadap kompetensi profesional guru SD Al Ikhlas Cipete, yang berarti $\mathrm{Ha}$ diterima dan Ho ditolak.

\section{DAFTAR PUSTAKA}

Aribowo., Su'ad. Dan Madjdi, Achmad Hilal. 2020. Pengaruh Supervisi Akademik dan Pelayihan Penelitian Tindakan Kelas Terhadap Kompetensi Profesional Se-Kecamatan Undaan Kabupaten Kudus. Jurnal Ilmiah Kependidikan. Volume 10 Nomor 2 Tahun 2020. ISSN 2087-9385.

Arikunto, Suharsimi. 2016. Prosedur Penelitian suatu Tindakan Praktik. Jakarta: PT Rineka Cipta.
Bangun, Wilson. 2012. Manajemen Sumber Daya Manusia. Jakarta: Penerbit Erlangga.

Kurniawan, Agus. 2017. Pengaruh Motivasi Kerja dan Kesejahteraan Guru Terhadap Kompetensi Profesional Guru Pada MIN Air Joman Dan MIS MIPI Binjai Serbangan Kabupaten Asahan. Tesis : Universitas Islam Negeri Sumatera Utara.

Muhajirin. Prihatin, Titi., dan Yusuf, Amin. 2017. Pengaruh Supervisi Akademik dan Partisipasi Guru Pada MGMP Melalui Motivasi Kerja Terhadap Profesionalisme Guru SMA/MA. Educational Management. P.ISSN : 22527001.

Mulyasa, E. 2013. Standar Kompetensi dan Sertifikasi Guru. Bandung: PT Remaja Rosdakarya.

2015. Manajemen dan Kepemimpinan Kepala Sekolah. Jakarta: Remaja Rosdakarya. Cetakan Ketiga.

Sagala, Syaiful. 2013. Kemampuan Profesional Guru dan Tenaga Kependidikan. Bandung: Alfabeta.

Sugiyono. 2019. Metode Penelitian Pendidikan Kuantitatif, Kualitatif dan R\&D. Bandung: Alfabeta.

Supardi. 2014. Kinerja Guru. Jakarta: PT Raja Grafindo Persada.

Suryadi, Ace. 2014. Pendidikan Indonesia Menuju 2015. Bandung: PT Remaja Rosdakarya

Undang-undang Rl No. 14 Tahun 2005 tentang Guru dan Dosen. Diperbanyak oleh PB PGRI.

Undang-undang Rl No. 20 Tahun 2003 tentang Sistem Pendidikan 
Nasional. Semarang: CV. Duta Nusindo.

Uno, Hamzah B. 2013. Teori Motivasi dan Pengukurannya. Jakarta: Bumi Aksara.

(Halaman sengaja dikosongkan) 

(KAHPI)

p-ISSN 2685-8401 e-ISSN 2685-7502 